\title{
Large-Scale Geothermal Collector Systems for 5th Generation District Heating and Cooling Networks
}

\author{
Robin Zeh ${ }^{1, *}$, Björn Ohlsen ${ }^{2}$, David Philipp ${ }^{2}$, David Bertermann ${ }^{3}$, Tim Kotz $^{2}$, Nikola Jocić ${ }^{3}$ \\ and Volker Stockinger 1,2 \\ 1 Department of Energy and Building, Technische Hochschule Nürnberg Georg Simon Ohm, \\ 90489 Nuremberg, Germany; volker.stockinger@th-nuernberg.de or v.stockinger@energie-plus-concept.de \\ 2 Energie PLUS Concept GmbH, 90402 Nuremberg, Germany; b.ohlsen@energie-plus-concept.de (B.O.); \\ d.philipp@energie-plus-concept.de (D.P.); t.kotz@energie-plus-concept.de (T.K.) \\ 3 Geo-Centre of Northern Bavaria, Chair of Geology, Friedrich-Alexander University Erlangen-Nuremberg, \\ 91054 Erlangen, Germany; david.bertermann@fau.de (D.B.); nikola.jocic@fau.de (N.J.) \\ * Correspondence: robin.zeh@th-nuernberg.de; Tel.: +49-911-5880-1848
}

check for updates

Citation: Zeh, R.; Ohlsen, B.; Philipp, D.; Bertermann, D.; Kotz, T.; Jocić, N.; Stockinger, V. Large-Scale Geothermal Collector Systems for 5 th Generation District Heating and Cooling Networks. Sustainability 2021, 13, 6035. https://doi.org/10.3390/ su13116035

Academic Editors: Marc A. Rosen, Ali Khosravi, Mohammad Malekan and Juan Jose Garcia Pabon

Received: 31 March 2021

Accepted: 22 May 2021

Published: 27 May 2021

Publisher's Note: MDPI stays neutral with regard to jurisdictional claims in published maps and institutional affiliations.

Copyright: (c) 2021 by the authors. Licensee MDPI, Basel, Switzerland. This article is an open access article distributed under the terms and conditions of the Creative Commons Attribution (CC BY) license (https:// creativecommons.org/licenses/by/ $4.0 /)$.

\begin{abstract}
Low temperature district heating and cooling networks (5GDHC) in combination with very shallow geothermal energy potentials enable the complete renewable heating and cooling supply of settlements up to entire city districts. With the help of 5GDHC, heating and cooling can be distributed at a low temperature level with almost no distribution losses and made useable to consumers via decentralized heat pumps (HP). Numerous renewable heat sources, from wastewater heat exchangers and low-temperature industrial waste heat to borehole heat exchangers and large-scale geothermal collector systems (LSC), can be used for these networks. The use of large-scale geothermal collector systems also offers the opportunity to shift heating and cooling loads seasonally, contributing to flexibility in the heating network. In addition, the soil can be cooled below freezing point due to the strong regeneration caused by the solar irradiation. Multilayer geothermal collector systems can be used to deliberately generate excessive cooling of individual areas in order to provide cooling energy for residential buildings, office complexes or industrial applications. Planning these systems requires expertise and understanding regarding the interaction of these technologies in the overall system. This paper provides a summary of experience in planning 5GDHC with large-scale geothermal collector systems as well as other renewable heat sources.
\end{abstract}

Keywords: 5GDHC; large-scale geothermal collector; very shallow geothermal potential; vSGP

\section{Introduction}

Due to their high demand for energy and raw materials, cities contribute significantly to climate change. The urbanization is one of the main drivers of these increasing demands in combination with economic growth [1]. Therefore, the international community of states has decided with the "Sustainable Development Goal 11" of the "Agenda 2030" to make cities and human settlements inclusive, safe, resilient and sustainable by 2030 [2] (p. 46). In this context, one of the greatest challenges in Europe and in total for the whole world is the climate-neutral energy supply of cities. Conolly et al. [3] examined six different strategies proposed in the European Energy Roadmap 2050 for the energy system. The focus is mostly up to the electricity sector. They showed that there is an enormous potential of energy savings with district heating when it comes to renewable energy resources, heat savings or heat recycling. In addition to this by the end of 2020 the European council tightened the regulations to a net domestic reduction of at least $55 \%$ in greenhouse gas emissions in the year 2030 compared to 1990 [4] (p. 5).

Because of the need to reduce greenhouse gases Rezaie et al. [5] reviewed the development of heat networks with the goal to find improvements for future systems. Heat networks can therefore be classified with circulating fluid, thermal application, network 
size, and energy source. In addition, district heating systems are more economic for higher density and more populated regions such as urban structures. According to Lund et al. [6], they can be classified into 1st to 4th Generation to show the improvements over the last 100 years. These start with 1st Generation and coal fired steam systems up to 4th Generation with highly efficient renewable systems and temperature levels less than $100^{\circ} \mathrm{C}$.

As shown in Figure 1, the development of heating networks over the last 150 years indicates a trend from centralized fossil heat sources, with very high heat losses, to decentralized renewable energy sources at low temperature levels with almost no heat losses in smart thermal grids. In addition, in Table 1 the typical features of the different generations are compared. With 5th Generation first time non insulated polymer pipes with antifreeze as heat carrier are used. This process leads to strong $\mathrm{CO}_{2}$ savings.

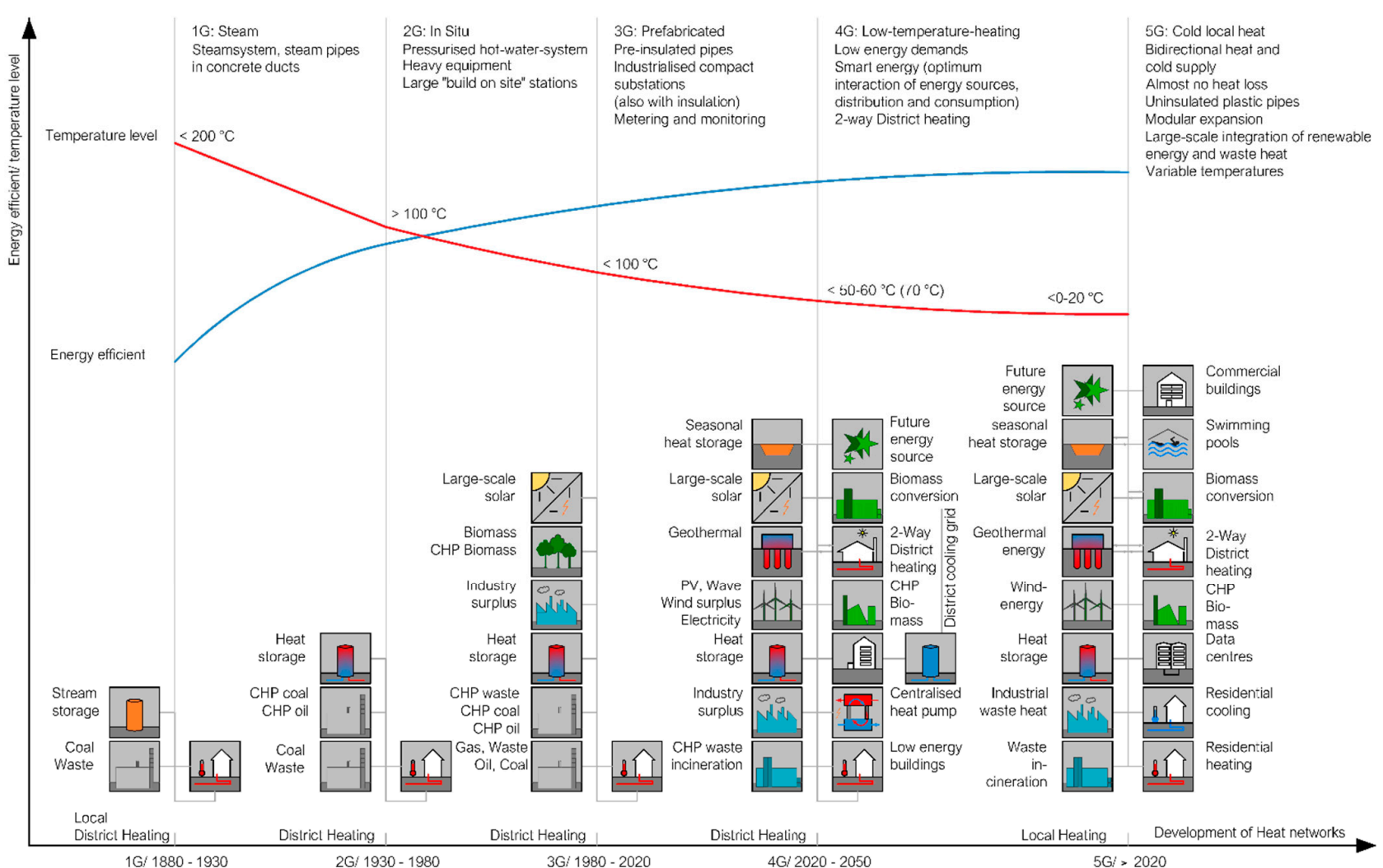

Figure 1. District heating networks from the first to the 5th generation over the last 150 years (Source: Further development of the graphic in accordance with Lund et al. 2014 [6] (p. 9.)).

Table 1. Typical features of district heating networks from first to 5th generation (Source: [6-8] (p. $120.6 \mathrm{ff})$ ).

\begin{tabular}{|c|c|c|c|c|c|}
\hline & $1 \mathrm{G}$ & $2 \mathrm{G}$ & $3 G$ & $4 \mathrm{G}$ & $5 G$ \\
\hline mostly used & 1880-1930 & 1930-1980 & 1970-now & currently used & currently used \\
\hline motivation & $\begin{array}{l}\text { comfort, reduced } \\
\text { risk }\end{array}$ & fuel and cost savings & reliable heat supply & renewable energie & $\begin{array}{l}\text { renewable energie, } \\
\text { efficiency, cooling }\end{array}$ \\
\hline temperature level & $<200^{\circ} \mathrm{C}$ & $>100^{\circ} \mathrm{C}$ & $>100^{\circ} \mathrm{C}-70^{\circ} \mathrm{C}$ & $90^{\circ} \mathrm{C}-40^{\circ} \mathrm{C}$ & $20^{\circ} \mathrm{C}-<0^{\circ} \mathrm{C}$ \\
\hline $\begin{array}{l}\text { Temperature } \\
\text { spread }\end{array}$ & $20-60 \mathrm{~K}$ & $20-40 \mathrm{~K}$ & $20-40 \mathrm{~K}$ & $20-40 \mathrm{~K}$ & $3-6 \mathrm{~K}$ \\
\hline heat carrier & steam & pressurized hot water & $\begin{array}{l}\text { (pressurized) hot water, } \\
\text { often below } 100^{\circ} \mathrm{C}\end{array}$ & water & antifreeze \\
\hline $\begin{array}{l}\text { source of heat } \\
\text { (examples) }\end{array}$ & coal, CHP, boilers & coal, oil, CHP, boilers & $\begin{array}{l}\text { CHP, boilers, waste, } \\
\text { fossil-fired boilers }\end{array}$ & $\begin{array}{l}\text { waste heat, solar } \\
\text { thermal energy, } \\
\text { biomass, deep } \\
\text { geothermal energy }\end{array}$ & $\begin{array}{c}\text { waste heat, } \\
\text { geothermal energy, } \\
\text { savage water, river } \\
\text { water }\end{array}$ \\
\hline
\end{tabular}


Table 1. Cont.

\begin{tabular}{|c|c|c|c|c|c|}
\hline & $1 \mathrm{G}$ & $2 \mathrm{G}$ & $3 G$ & $4 \mathrm{G}$ & $5 \mathrm{G}$ \\
\hline heat distribution & steam pressure & centralized pumps & centralized pumps & $\begin{array}{l}\text { (de-)centralized } \\
\text { pumps }\end{array}$ & $\begin{array}{l}\text { (de-)centralized } \\
\text { pumps }\end{array}$ \\
\hline $\begin{array}{l}\text { Heat distribution } \\
\text { losses }\end{array}$ & very high & high & moderate & moderate & low/heat gain \\
\hline Pipe materials & $\begin{array}{l}\text { (on-site isolated) } \\
\text { steel pipes }\end{array}$ & $\begin{array}{c}\text { (on-site isolated) steel } \\
\text { pipes }\end{array}$ & pre-isolated steel pipes & $\begin{array}{c}\text { pre-isolated } \\
\text { steel/polymer pipes }\end{array}$ & $\begin{array}{l}\text { non-isolated polymer } \\
\text { pipes }\end{array}$ \\
\hline heat transfer & condensers & $\begin{array}{l}\text { tube-and-shell heat } \\
\text { exchangers }\end{array}$ & plate heat exchangers & plate heat exchangers & heat pumps \\
\hline $\begin{array}{l}\text { heating system } \\
\text { (radiators) }\end{array}$ & $\begin{array}{l}\text { high-temperature } \\
\text { radiators using } \\
\text { steam or water } \\
\quad\left(>90^{\circ} \mathrm{C}\right)\end{array}$ & $\begin{array}{l}\text { high-temperature } \\
\text { radiators using district } \\
\text { heating water direct or } \\
\text { indirect }\left(90^{\circ} \mathrm{C}\right)\end{array}$ & $\begin{array}{l}\text { medium-temperature } \\
\text { radiators using district } \\
\text { heating water direct or } \\
\text { indirect }\left(70{ }^{\circ} \mathrm{C}\right) \text {, floor } \\
\text { heating }\end{array}$ & $\begin{array}{l}\text { low-temperature } \\
\text { radiators }\left(50{ }^{\circ} \mathrm{C}\right) \\
\text { using water indirect, } \\
\text { floor heating }\end{array}$ & floor heating \\
\hline
\end{tabular}

With 4th Generation district heating networks (4GDH) smart thermal grids where introduced and efficiency increased by use of renewable energy sources [6]. In those smart thermal grids renewable energy can be shared within the whole district and the network itself can be used as heat storage [9]. Because of this the transition to $4 \mathrm{GDH}$ and implementation of smart thermal grids all over the world is inevitable.

When it comes to smart thermal grids and the use of waste heat there is one major problem. Energy at such low temperature levels cannot be used directly within 4GDH. Because of this, the 5GDHC with temperature levels around soil temperature as a descendant of 4GDH [10] was introduced and defined 2019 by Boesten et al. [11] and Buffa et al. [7]. Moreover, 5GDHC are decentralized, bidirectional, and close to ground temperature network systems with a direct exchange of warm and cold return flows [11]. This makes them ideal for integrating renewable energies-which are often also decentralized and at rather low temperatures. With temperature levels around soil temperature heat losses hardly occur in these systems [11]. By using geothermal systems as a heat source, heat gains can even be achieved by the distribution network [12] (p. 26). With the analysis of more than 40 different 5GDHC Buffa et al. showed that there are no stringent guidelines for planer and designer. There is a lack of understanding of how to integrate multiple distributed heat and cold sources in such a network. Theoretical analysis with several Modelica simulations were done by Bünning et al. [13]. Because of all the benefits renewable 5GDHC networks should be introduced all over the world.

This paper mainly investigates in large-scale geothermal collector systems (LSC) in combination with 5GDHC as a renewable heat source. These can be used as a heat source for 5GDHC networks in European countries showed by the example of Germany. Several collector systems are analysed. Moreover, the planning and design of these systems is addressed.

\section{Low Temperature District Heating and Cooling}

\subsection{Definition of $5 G D H C$}

With the help of successful research activities in the field of heat supply of settlement structures during the last years, more and more 5GDHC have been built in Europe. They serve as heat distribution networks of the current 5th generation [7], with low temperatures of below zero up to $20^{\circ} \mathrm{C}$ and usually low temperature spreads of 3-6 K [14]. Due to intermittent low system temperatures in the distribution network, a heat transfer medium (mostly water-glycol mixtures) with a lower freezing point than water is used as heat or cold transfer medium. The low temperature level in the distribution pipes can therefore be used for heating by heat pumps in residential buildings as well as for free or active cooling. Furthermore, the low system temperatures lead to hardly any distribution losses in the non-insulated pipelines. Moreover, there can be significant heat gains from the surrounding soil of the distribution pipe [12] (p. 26). 
Different renewable technologies can be used as heat sources for 5GDHC. These can be for example vertical ground heat exchanger fields, large-scale geothermal collector systems, wastewater heat exchangers and low-temperature waste heat from data centers or industrial processes. They are designed for the respective heating and cooling demands of the settlement to be supplied. Typically, the on-site available heat sources and their temperature levels are analyzed first. Then, the 5GDHC is planned in its dimension and temperature level to supply the buildings. The heat gains of the distribution pipes are taken into account in the final design of the available heat sources.

Positive interactions can occur between heat sources within the supply structure. For example, one type of building withdraws heat from the grid at one time and feeds waste heat to another [7]. A user that draws energy from the grid and feeds it back in at different times is called a "prosumer" [11] (p. 131), [15]. A residential building that extracts heat in winter but extracts cooling in the summer months represents a typical prosumer. This effect can also occur across multiple different consumers, for example when a housing development is coupled with a data center. When prosumers are interconnected, it is referred to as a bidirectional network, since the energy flow is not permanently rectified from the energy source to the users [14] (p. 6). Heating and cooling demand by different users do not always occur simultaneously and in the same amount within the network, so different energy sources must be used depending on local supply and availability [16]. Another advantage of 5GDHC is their modularity and flexibility in the face of changing boundary conditions. Additional consumers or energy sources can be integrated into the network afterwards [7]. However, 5GDHC also have disadvantages. With the low temperature difference between the pipes (3-6 K), high volume flows are required. To keep the pressure loss in the system as low as possible, large pipe diameters are required. This leads to higher investment costs for the large pipe dimensions and the heat transfer medium. In addition, more space for laying the pipes is required in the usually very narrow earth body below the street. Depending on the number of consumers and the energy demand density, a network can be designed to be active or passive.

\subsection{Passive 5GDHC}

In a passive network, the circulation within the distribution network is achieved solely by the feed pumps integrated in the heat pumps. Therefore, the pressure loss is the most important design feature in the planning state. This depends mostly on the individual components such as piping, house substation, distributor, line regulating valve, heat source, heat transfer medium, etc. Since passive networks are operated without central network pumps, the feed pumps of the decentralized HP's must be able to overcome the pressure loss in the overall system in order to ensure the circulation of the heat transfer medium. If no minimum flow can be ensured in every part of the network, a hydraulic short circuit will occur [17]. If all HPs are operated simultaneously, the maximum flow is achieved. In order to keep the pressure loss as low as possible, large pipe diameters and short pipe lengths should be selected. Due to the large pipe dimensions, it must be ensured that the fittings are available in the appropriate dimensions. In addition, more space is required when laying below the street. Consultation with the other trades (water, electricity, wastewater, etc.) is necessary.

A major advantage of passive 5GDHC is the fact that no energy center is required. Only a small technical building is needed, in which pressure maintenance, refilling and ideally degassing are integrated. This can also be arranged in one of the connected buildings. Together with the elimination of central feed pumps, this leads to long-term cost-effective and energy-efficient operations. However, it cannot be easily expanded at a later date. Additional heat sources or network sections can usually not be integrated. A typical passive $5 \mathrm{GDHC}$ is used in smaller construction areas with short pipeline distances between the consumers and smaller heat sources. They are in the order of magnitude of up to 100 heat consumers. This is dimensioned depending on the distance of the heat source to the building area as well as the planned development (multi-family house, single-family house, 
etc.). The lower the customer-specific heat demand, the more customers can be supplied by this system. With a high amount of multi-family houses, such a network will quickly reach its hydraulic limits. The heat sources should be located next to the consumers.

\subsection{Active $5 G D H C$}

In an active 5GDHC, similar to conventional district heating networks, central pumps are usually installed inside an energy center. With central feeding pumps, the delivery head in the pipe network can be freely selected, which means that the pressure loss is not the central planning variable like in a passive network. Therefore, the pipe diameter can be dimensioned significantly smaller. Furthermore, it is possible to expand the heating network with additional heat sources or network sections later on. However, this should already be considered during the initial planning, so that the energy center and the heat pumps with their temperature spread of 3-6 K are designed accordingly. The energy center usually contains the central network pumps, pressure equalization tanks, motorized butterfly valves and the network degassing system. To enable maintenance and possible malfunctions without downtime, the pumps are designed redundantly. This means that several identical pumps are installed in parallel and operated alternately.

In each house substation, a control and regulation unit (motorized butterfly valve) is placed to prevent permanent flow. There is only a flow through the HP during its operation. This must be taken into account during planning in order to minimize the pressure loss in the overall system and thus the wear and electricity demand of the central pumps.

The feeding pumps can be operated via differential pressure, so they adjust their output to the pressure present in the network. Therefore, various heat sources can be developed further away from the construction area, which provides more flexibility in the selection of potential heat sources. However, the permanent circulation of the heat network means that electrical energy is required the whole time. This leads to efficiency reductions in the overall system.

An active 5GDHC is used for spatially extensive construction areas with more than 50, up to many hundreds of heat consumers. Several remote heat sources can be linked bidirectional, allowing heating and cooling energy to be shifted. If it is not possible to provide sufficient space for large pipe dimensions when installing the network lines (passive network), an active network is also suitable for smaller supply areas.

\subsection{Requirements of 5GDHC Network Pipes}

There are special needs for the pipe material and the installation process. The low temperature network pipes material is either PE 100-HD (high density) or PE 100-RC (resistant to crack). PE 100-HD is the same as it is used for drinking water supply. With this material there is the need for laying the pipes into a sand layer to avoid damages during backfilling. With PE 100-RC, there is no need for a sand layer. This material is characterized by very high lifetime, high safety against damaging or point load and stress crack resistance. In every case the pipe is constructed without insulation material. The distance between the two pipes in the ground should be at least $0.5 \mathrm{~m}$ and $1.2-1.5 \mathrm{~m}$ in depth, so there are no natural freezing issues. The distance to the drink water supply should be at least 0.7-1.0 $\mathrm{m}$ to avoid interactions. To connect those PE-Pipes during construction, there are two connection processes: mirror welding or electrofusion coupling.

\section{Large-Scale Geothermal Collector System (LSC)}

\subsection{Definition of Very Shallow Geothermal Potential}

The 5GDHC networks aspire to connect to renewable energy sources [18], including geothermal sources $[17,19]$. Shallow geothermal sources are suitable for application regarding 5GDHC networks. They are generally defined by depth and encompass those energy achieved from the sources up to $400 \mathrm{~m}$ [20] (p. 1). Sources from shallower depths are more practical to exploit. Therefore, very shallow geothermal potentials (vSGP) should 
be segregated as a geothermal layer with special characteristics. A graphic overview of very shallow, shallow, and deep geothermal sources is shown Figure 2

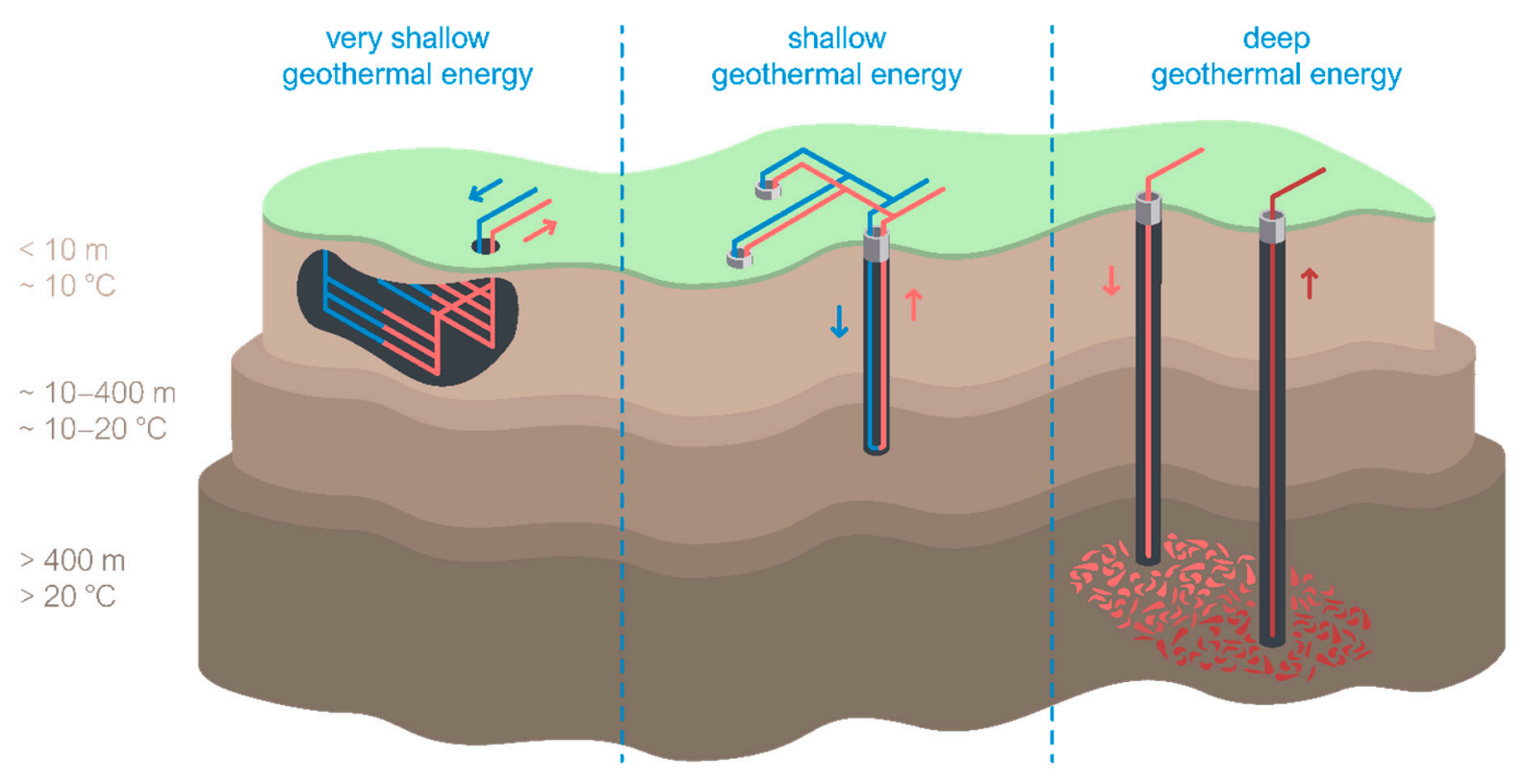

Figure 2. Very shallow, shallow and deep geothermal potential classification.

vSGPs are those acquired by depth less than $10 \mathrm{~m}$ [21]. This depth range relevant for very shallow geothermal systems can be divided further in three layers: 0-3 m, 3-6 m, and $6-10 \mathrm{~m}$ [22], which differ by physical soil properties. Thus, for vSGPs mainly soil parameters are decisive, whereas for vertical shallow geothermal systems largely the geologic rock strata is critical for their heat extraction potential. The role of soil regarding geothermal use is also discussed by Di Sipio and Bertermann [23]. Thermal properties of soil are the crucial parameters that affect heat extraction of the very shallow geothermal systems. These properties such as thermal conductivity, thermal diffusivity and heat capacity are strongly affected by the physical soil parameters, namely bulk density, water content, and soil texture defined by grain size distribution $[24,25]$. Climate factors, such as solar irradiation and precipitation, also have certain influence on vSGP $[21,26]$. Heat input from the earth's interior (terrestrial heat flow) is negligible in the shallower soil layers. However, the influence of terrestrial heat flow becomes more important in the regeneration behavior of the soil with increasing depth, while the influence of solar irradiation is opposite.

The vSGP systems are principally horizontally installed geothermal systems that utilize the heat potential on the earth's surface rather than at depth. These are horizontal ground heat exchangers, such as geothermal collectors in the classic single pipe installation or tube mats, but also special designs such as trench collectors, heat baskets, and comparable modular collector systems up to a maximum depth of $10 \mathrm{~m}$.

Geothermal systems for heating and cooling have lower operational costs compared to other systems [27]. Horizontal ground heat exchangers have advantages in lower installation costs and lower drilling technology requirement, therefore are widely used in engineering and more suitable compared with the vertical ground heat exchangers [28]. When sufficient ground area is available, horizontal ground heat exchangers provide the most cost-effective solution for heating and cooling [29].

In Germany, for instance, energy for heating and cooling achieved from vSGPs has been on a permanent rising trend in the recent past. The share of shallow geothermal energy and the environmental heat in total energy for heating and cooling achieved from renewable sources was around 9\% in 2020 [30,31]. Further, 20,500 ground source heat pumps focused on closed loop systems were installed in Germany in 2020 [32]. This is a 
rise of $17 \%$ compared to 2019 . It is realistic to assume that approximately $30 \%$ of these ground source heat pumps operate with horizontal systems. Due to drilling restriction and ground water protection regulation horizontal systems and their special forms are receiving more attention.

\subsection{Definition Large-Scale Geothermal Collector System}

A very shallow large-scale geothermal collector system (LSC) is distinguished from smaller systems in particular by its size and performance. Typical large-scale geothermal collector systems supply entire settlements with heating and cooling energy via 5GDHC [17] (p. 3) by using the vSGP. There are also large-scale geothermal collector systems which are built below the buildings [33] (p. 2), [34] (p. 50). The following parameters describe the large-scale geothermal collector classification. At least one of the criteria as shown in Figure 3 needs to be fulfilled:

- $\quad \geq 1.000 \mathrm{~m}^{2}$ area

- $\quad \geq 25 \mathrm{~kW}$ maximum source power

- $\quad \geq 50 \mathrm{MWh} / \mathrm{y}$ source heat extraction

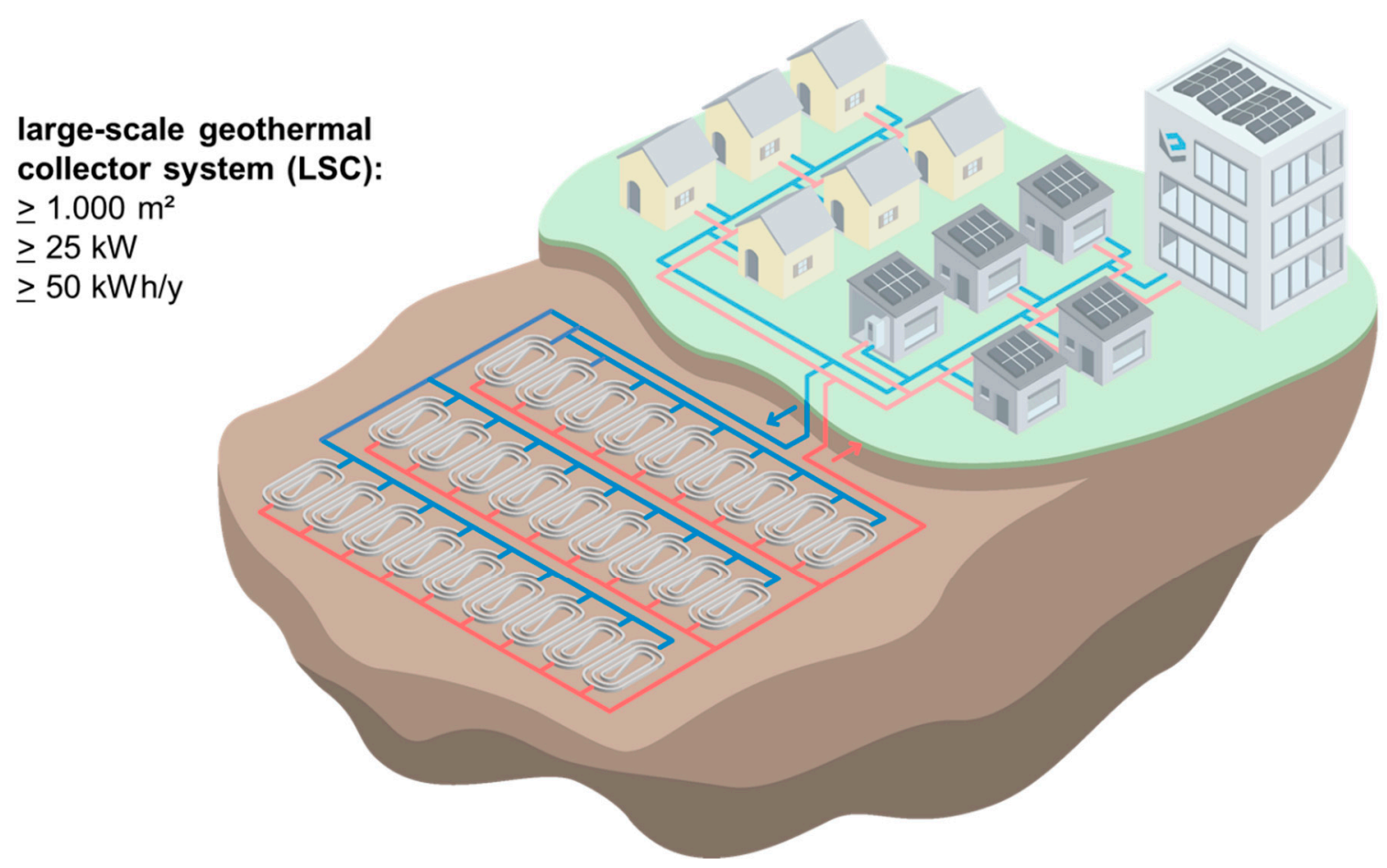

Figure 3. Representation and definition of large-scale collector systems (LSC).

Large-scale geothermal collectors differ from small systems, which are usually built for individual buildings, in their size and complexity. They can also be constructed in multiple horizontal layers. Due to the large number of pipelines and distribution shafts, the pressure loss must always be taken into account in detail and optimized for the system, so that all pipelines are evenly flown through with heat transfer medium and thus, an even heat extraction can be guaranteed. Within the large-scale geothermal collector system, the mutual influence of the individual collectors, which affects the heat extraction behavior, also comes into play. This requires more detailed planning, usually with the help of simulation programs.

Previous LSC's usually consist of modular trench collectors, distribution shafts and an energy center. The advantage of modular trench collectors is that the pressure loss is known and stays the same for all modules within the system. By connecting several modules in parallel on a collector line, this can be dimensioned, and the number of distribution shafts 
can be determined. In multi-layer geothermal collector systems, the collector layers are usually connected separately. This means that every layer can be controlled separately during operation in order to guarantee targeted use of the advantages of the multi-layer system (seasonal heat and cold storage).

\subsection{Advantages and Disadvantages of Large-Scale Geothermal Collector Systems}

The advantage of the area development down to a depth of a few meters lies in the high regeneration potential through the climate, primarily the solar irradiation. Thus, over short periods of time, heat can be extracted from the soil to below the freezing point of the moisture present in the soil. In this way the heat energy, which is released in the phase transformation from water to ice, is tapped by the LSC. The cooled soil is naturally regenerated again by solar irradiation and precipitation. Subsequently, the supplied regeneration heat can be extracted from the soil again in the next heating season. For natural regeneration through the climate, it is important that solar irradiation and precipitation can enter the soil as unhindered as possible. It is also important to note that the phase transformation of liquid water to ice causes the pores of the soil to expand. For this reason, care must be taken during planning to ensure that the ice of the large-scale geothermal collector does not merge with the natural icing on the surface. This can possibly do damage to overbuilt or adjacent structures.

It is almost impossible to cool the surrounding soil of a large geothermal single-layer collector at a depth of 1.5-2 $\mathrm{m}$ with the heat extraction for the heat supply of classical heat applications to such an extent that it cannot be regenerated again over the summer months at a location in temperate latitudes (four seasons, sufficient precipitation) [35]. The situation is different with heat baskets where a massive block of ice can form in the center that cannot be regenerated naturally, without the supply of thermal energy (usually in the form of waste heat). The same applies to multi-layer collector systems (e.g., frozen soil storage [35]), since the natural regeneration is "shut off" by solar irradiation and precipitation from the uppermost collector layer. However, this effect can also be exploited by deliberately generating excessive cooling of individual areas in order to provide cooling energy for residential buildings, office complexes or industrial applications and to use the heat released in the process of regeneration of the frozen areas [36] (p. 6).

Another advantage of large-scale geothermal collector systems is the low efficiency loss due to mutual influences. Efficiency losses may occur in the center of a LSC system, but regeneration is always ensured due to regeneration by the surface conditions (solar irradiation and precipitation) and only to a lesser extent by the terrestrial heat flow. Finally, it should be mentioned that the yield of geothermal collectors can be estimated accurately in advance, since analyses of the upper soil layers can be carried out easily and at low cost [24].

The main disadvantage of the vSGP to the shallow systems is that their heat potential is subject to seasonal fluctuations, which means that the lowest natural geothermal potential is available in winter. Geothermal systems using the vSGP tap the soil all around the plant, which is why the area demand is often higher than the demand for other geothermal systems.

\subsection{Application Scenarios of Large-Scale Collector Systems}

A large-scale geothermal collector system is in constant competition or even in combination with other sustainable forms of heat supply such as ground heat exchangers, solar thermal energy, biomass or waste heat sources (industrial waste heat, wastewater heat, etc.). A large-scale geothermal collector is a good choice, especially if the overall system can be operated at a low temperature level via 5GDHC and not every building can have its own heat source, e.g., due to space constraints. If larger open areas are available during the development of the building area, a LSC can be considered. It can be placed, for example, below a rainwater retention basin, below sports fields, in compensation areas or in agricultural areas, in order to enable dual use of the areas. 
If the large-scale geothermal collector is operated via 5GDHC, it can provide both heating and cooling energy for the settlement. For example, in the case of a multi-layer collector installation, it can show its benefits by utilizing the phase transformation of the soil moisture. As a result of the increased heat extraction up to the local icing of the soil, the specific heat extraction per square meter of soil surface increases [36] (pp. 6-7), [37] (pp. 657-658). This process leads to savings in area demand of vSGP systems. However, multi-layer collector systems can only be used if the settlement requires thermal energy in the winter months and sufficient cooling energy in the summer months. In addition, it must be ensured that regular freezing and thawing does not cause the soil to permanently lose moisture. Dry regions are unsuitable for this, unless additional moisture is deliberately introduced into the soil via special structures (e.g., drainage pipes).

The drilling of borehole heat exchanger systems is usually subject to special legal approval requirements, which are checked in advance. In Germany, for example, it may be prohibited to develop a vertical heat exchanger via a borehole for reasons of groundwater protection or due to mining law requirements. In the case of large-scale geothermal collector systems, requirements under licensing law must also be checked. However, the requirements are usually much less stringent and can be met. Thus, the development of settlements with regenerative low-temperature heat can usually be carried out in areas with a special legal situation.

A large-scale geothermal collector can act as an intermediate storage unit in a 5GDHC. Low-temperature waste heat from industrial processes or from a wastewater heat exchanger can also be integrated. Seasonal load peaks, both in generation and consumption, can be temporarily stored within a LSC and then provided as needed.

\section{Examples of 5GDHC with Different Heat Sources}

The combination of large-scale geothermal collector systems with 5GDHC networks is a very young technology. Because of this, yet there are not very much of these systems built around Europe. In Germany there is a trend in sight, that these systems are increasingly used with 5GDHC. Projects in different European countries are also in sight. The following examples show the use of different heat sources for 5GDHC around Europe and the use of several large-scale geothermal collector systems in Germany.

\subsection{Examples of Different Heat Sources for European 5GDHC Networks}

Figure 4 shows the different locations of existing low temperature networks in Europe according to Buffa et al. [7] with six supplemented projects which are large-scale geothermal collector systems. It can be seen that the use of ground water and shallow geothermal energy are the most common in Europe. As Buffa et al. have already shown, Switzerland and Germany are pioneers in 5GDHC. Switzerland relies mainly on groundwater and shallow geothermal energy. In Germany, the focus is increasingly on shallow and very shallow geothermal energy to supply heat grids. In other EU countries, ground water and sea water are often used as heat sources. Especially in France there are a few low temperature networks with ground water as the heat source which are not displayed in the figure. The lack of 5GDHCs in Eastern Europe is noticeable. One reason for this is that there are common district heating systems from the communist era in many Eastern European cities. They are often characterized by very high temperatures, fossil fuels, and outdated technologies [38]. 


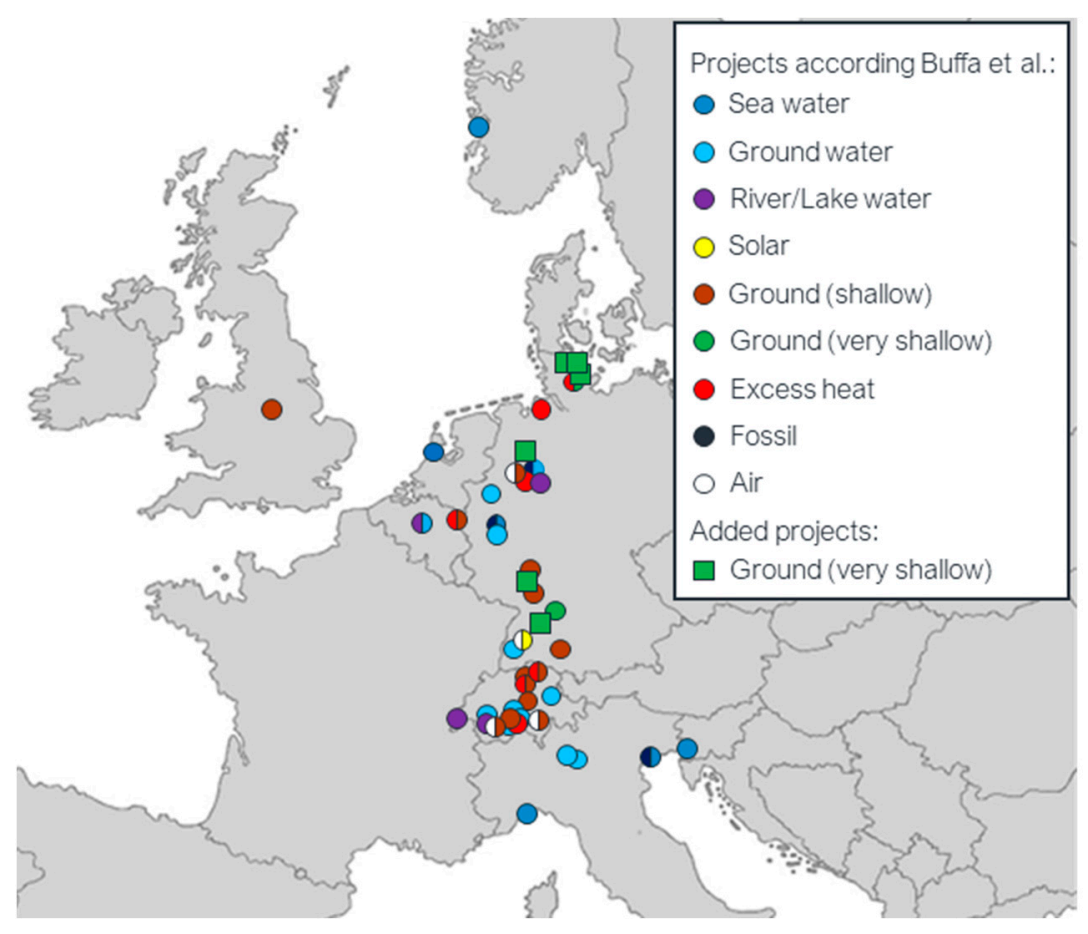

Figure 4. Abstract of existing low temperature heating networks in Europe and their main heat source (Source europe map: kartoxjm (fotolia)/europakarte.org; data source: based on [7]).

\subsection{Examples of 5GDHC in Connection with Large-Scale Geothermal Collector Systems in Germany}

\subsubsection{Agrothermal Collector with Passive 5GDHC in Wüstenrot (Germany)}

The first large-scale agrothermal collector in $1.5 \mathrm{~m}$ depth was built in 2011. Since then, $4400 \mathrm{~m}^{2}$ of agricultural land have been used to provide heating and cooling energy for about 25 residential buildings in Wüstenrot (see Figure 5). The project was the first one demonstrating the possibilities of dual use for heat provision and agricultural cultivation. This project showed the potentials of heat and cold supply of the very shallow geothermal energy zone in connection with a 5GDHC [17]. The original plan was to increase the size of the collector system when the neighborhood is going to be expanded. However, due to the "high" temperature levels of the 5GDHC of $2-16^{\circ} \mathrm{C}$, the $4400 \mathrm{~m}^{2}$ collector area is sufficient for the entire district. Even though the additional buildings have been connected to the $5 \mathrm{GDHC}$, the system temperature is still permanently above $0{ }^{\circ} \mathrm{C}$. This means that the heat potential available in the phase transformation of the soil moisture does not even have to be used. Consequently, an additional reserve for expansions of the construction area is given.

In addition to the agrothermal collector, one of the first 5GDHC in Germany was created with 23 residential buildings. Every building is equipped with a heat pump (different heat pumps from 6-22 kW power) and a photovoltaic system (from 5-28 kWp, depending on the roof size). The area is constructed as a plus energy settlement, which means that the photovoltaic systems on the roof produces more energy during the year than the buildings are using. In addition, the buildings envelop is heavily insulated. The heat pumps are connected with the 5GDHC, so every building is supplied with heating and free cooling by the $500 \mathrm{~m}$ long network in combination with the collector system. Because of the short pipe length and the nearby collector system, the distribution network was built as a passive $5 \mathrm{GDHC}$. The main network pipes were designed very large with a diameter of DN250 in order to keep the pressure loss as low as possible. This ensures that the feeding pumps of the decentralized heat pumps can overcome the pressure loss in every part of the distribution network. The HPs have operated with an annual coefficient of performance of more than 4.0 since 2011. 

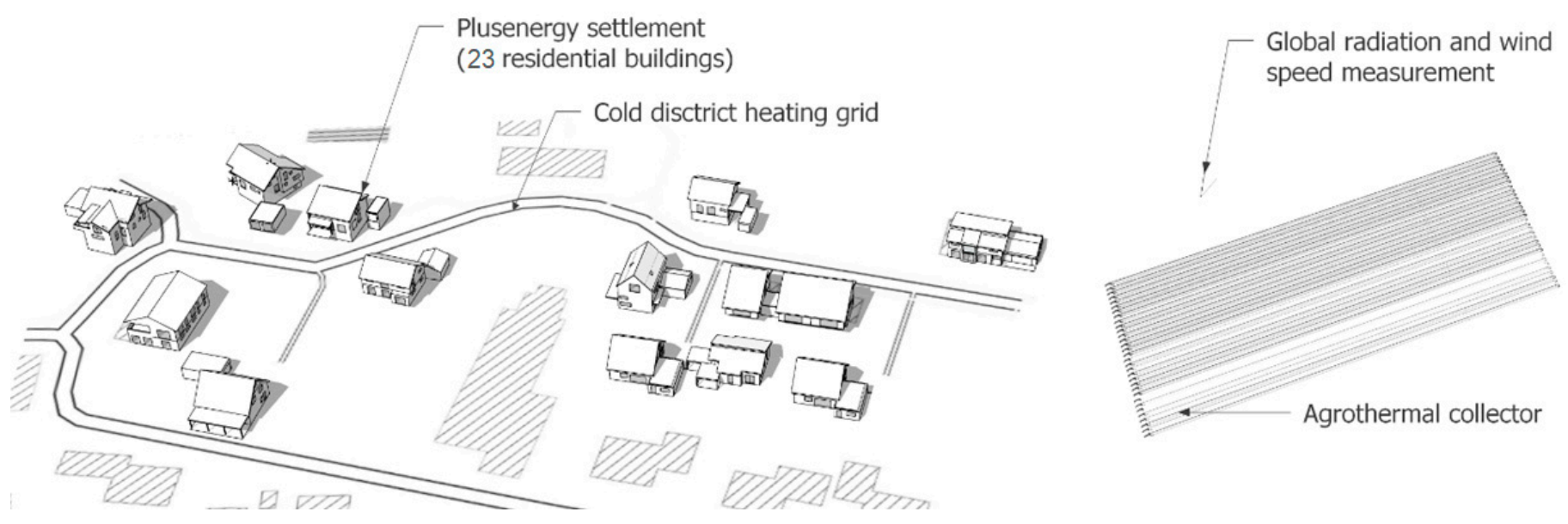

Figure 5. The Plus Energy Settlement with agrothermal heat collector (right) (Source: Brennenstuhl et al. [17]).

4.2.2. Large-Scale Geothermal Collector System with Active 5GDHC in Bad Nauheim (Germany)

In 2019, the largest geothermal collector system in Germany to date was built in Bad Nauheim. It is the main energy source for the new housing settlement with more than 400 residential units. A total of $22,000 \mathrm{~m}^{2}$ of geothermal collector area, distributed over two layers (1.5 m and $3.0 \mathrm{~m}$ depth) of $11,000 \mathrm{~m}^{2}$ each, was installed in the ground (see Figure 6). Together with the approximately $6 \mathrm{~km}$ long active 5GDHC the system has to provide about 2.3 GWh of source heat per year. These are the objects of investigation of the four-year research project "KNW-Opt" (Grant N.: 03EN3020B).
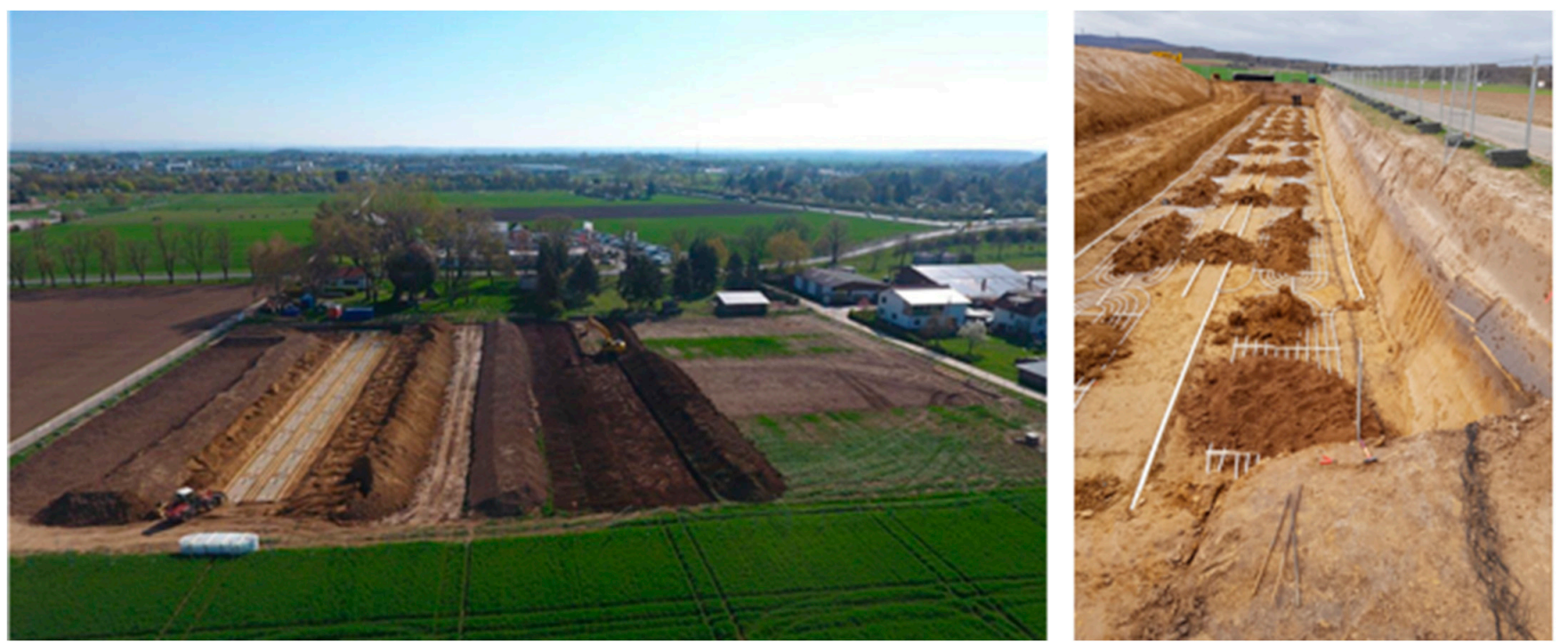

Figure 6. Construction site of the multilayer collector system in Bad Nauheim (Source: Steinhäuser GmbH \& Co. KG, Bischberg, Germany).

The heat gains from the collector and the distribution network are made usable for single-family and multi-family houses with decentral HPs in every building. Because of the multilayer installation and the expected network temperatures, free cooling of the residential buildings is possible during the summer months. According to initial studies, the temperatures between the two geothermal collector layers will be below freezing in the late winter months, which results in significant icing around the collector system. This icing remains in the system until the summer months and serves cooling energy for the buildings. Free cooling enables the transfer of the buildings' waste heat into the system, which can 
regenerate the collector system. The large-scale geothermal collector system was installed in an agricultural field which is already being cultivated again after the installation of the collector system [16] (p. 56).

The construction area is connected to the double-layer LSC system via an approximately $600 \mathrm{~m}$ long collector line (DN400). The length of the 5GDHC is more than $6 \mathrm{~km}$ in total. Three redundantly installed feeding pumps ensure permanent flow of the 5GDHC. One of the three pumps runs continuously to guarantee minimal network mixing. At full heat consumption two of the three pressure-controlled pumps run at full capacity. The pumps are continuously rotated so that wear is evenly divided among all three network pumps. Upstream of the decentralized heat pumps a motorized butterfly valve ensures that the volume flow only occurs when heat is actually needed. The whole system is controlled by the energy center next to the large-scale geothermal collector system.

4.2.3. Geothermal Collector with Air-Cooled Chiller Plant and Active 5GDHC in Neustadt am Rübenberge (Germany)

In "Neustadt am Rübenberge" a large-scale geothermal collector system was built with an area of around $3000 \mathrm{~m}^{2}$ below a rainwater retention basin in 2020. The geothermal collector area is installed at a depth of $1.50 \mathrm{~m}$ below the rainwater retention basin (see Figure 7). The annual heat energy required in the construction area is provided by the geothermal collector area in combination with an air-cooled chiller plant and the 5GDHC. If the air temperature is higher than the network temperature, heat can be extracted from the air via the heat transfer surface of the air-cooled chiller plant. This principle can be applied particularly well in the transition period (spring) when the air temperature already rises above $15^{\circ} \mathrm{C}$ while the ground and the heat transfer medium is still at a lower temperature level. From this point on, the 5GDHC and the neighborhood are supplied with heat from the air. This also improves the natural regeneration of the collector during the summer months because no heat is extracted. In addition, excess heat from the air can contribute to the regeneration of the large-scale geothermal collector system. However, it should not be too much regeneration energy during the warm months in order to provide free cooling at a directly usable temperature level. Wirtz et al. [39] (p. 25) showed that an optimum temperature for free cooling is around $14{ }^{\circ} \mathrm{C}$. The two heat sources (geothermal collectors and air-cooled chiller plant) are hydraulically connected and therefore enable the shifting of energy loads. Together with the 5GDHC, the consumers in the construction area are supplied with heating and cooling energy.

The 5GDHC supplies single-family and multi-family houses. Due to the size of the project with about 100 residential units, the network was planned as an active network with central feeding pumps located in an energy center. According to the manufacturer's specifications the temperature spread of the heat pumps is $3 \mathrm{~K}$. The pipes were designed for the resulting volume flow. The integration of the two heat sources in addition to the size of the construction area is the reason why the overall system was designed as an active network. 


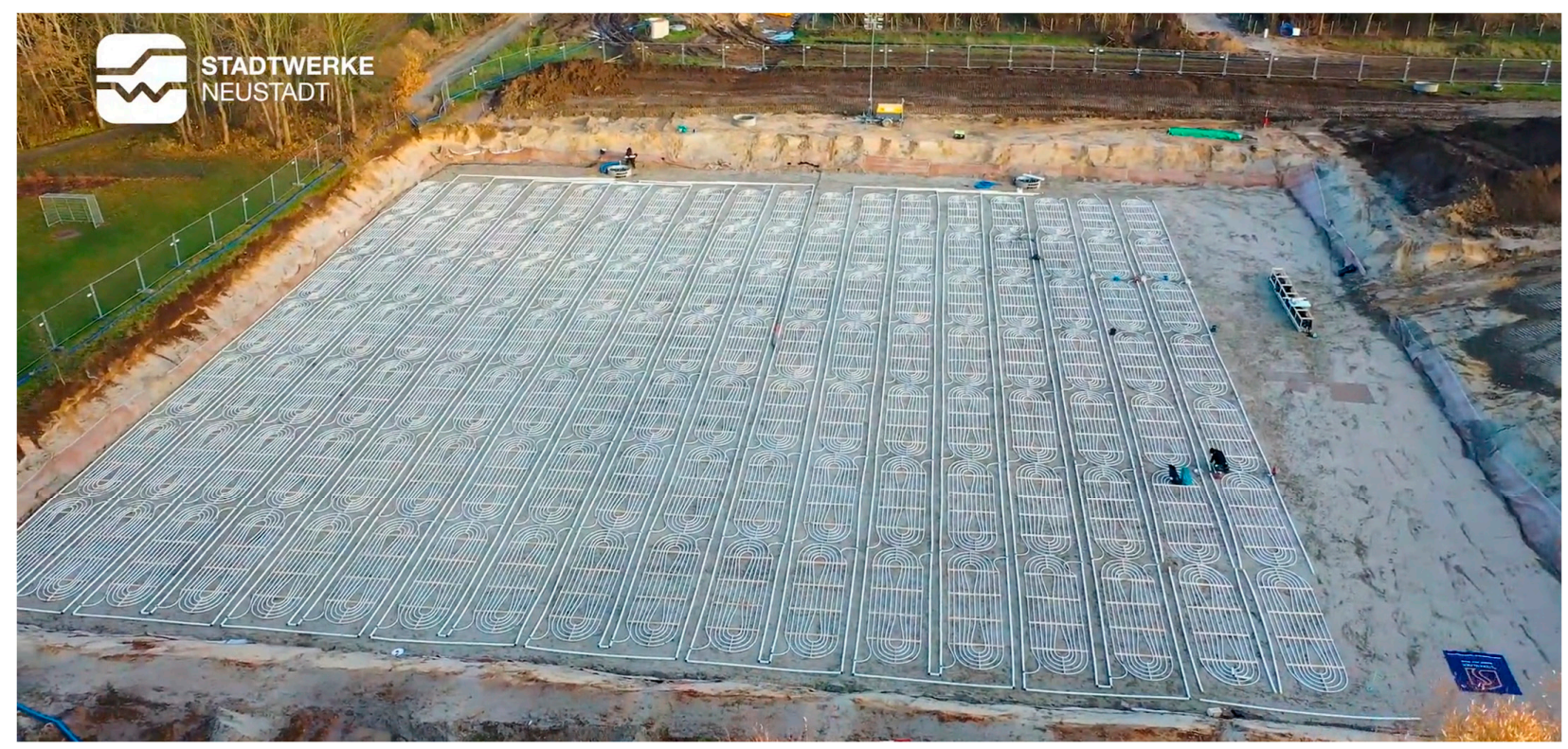

Figure 7. Aerial view of the installation of the approx. $3000 \mathrm{~m}^{2}$ large-scale geothermal collector system below the rainwater retention basin in Neustadt am Rübenberge (Source: Stadtwerke Neustadt a. Rbge. GmbH, Neustadt am Rübenberge, Germany).

\section{Interaction of the Technologies}

\subsection{Influence of the Residential Buildings on the Heat Source as Well as the Network}

The heating and cooling demand of the supplied buildings is the most significant factor for the 5GDHC. A low heat demand leads to a small heat source and small network dimensions. Therefore, every planning of the supply concepts always starts with the basic determination and the potential analysis.

Caused by continuously improving insulation properties of modern new buildings, the specific heat demand $\left(\mathrm{kWh} / \mathrm{m}^{2} \mathrm{y}\right)$ is decreasing, compared to existing buildings. Nowadays, highly efficient buildings are frequently equipped with surface heating systems such as underfloor or wall heating. Because of the reduced heating loads resulting from building insulation and larger heat transfer surfaces, supply temperatures of only about $35^{\circ} \mathrm{C}$ are required which ensures an efficient use of a HP within a 5GDHC network. In the transitional periods the solar heat gains, which are achieved through the windows in combination with the internal heat gains, are partially sufficient to achieve a comfortable room temperature. In the summer months. However, the large window areas also lead to an increase in cooling requirements even in temperate regions. This relationship is becoming more acute as outside temperatures continue to rise due to climate change.

In addition to the necessary heating and cooling quantities, heat is also required for domestic hot water. Legionella protection leads to hot water tanks with a minimum temperature of $55^{\circ} \mathrm{C}$ [40]. Depending on the country there are different regulations. According to this, in Germany the heat pump should provide a storage tank charging temperature of about $60^{\circ} \mathrm{C}$. To provide this temperature by a HP, its efficiency decreases because more electrical energy is required. This in turn reduces the proportion of source heat required from the 5GDHC. In consequence, 5GDHC cannot be considered in isolation from the heat consumers. There is always a reciprocal influence on the other network components.

Planning a 5GDHC means to continuously cross-check the coupled network components. Because of the complexity of the heat sources and their interactions with the users, the heat demand calculation is mostly a simulative approximation considering the environmental influences. A geothermal heat source, such as a large-scale geothermal collector, can be modeled in a hygrothermal simulation software, such as DELPHIN [41]. The behavior during heat extraction or injection as well as the behavior under regeneration 
by solar irradiation and precipitation can be investigated. Through metrological data analysis, the overall system can be aligned with the original expectations and optimized.

\subsection{Parallel Planning of 5GDHC Network and Heat Source (e.g., Large-Scale Geothermal Collector Systems)}

The parallel planning of 5GDHC with different heat sources requires a holistic approach. In contrast to conventional supply networks, which are planned monodirectionally from the energy center to the customers, a bidirectional approach is required for planning these networks [42]. In the planning of conventional heating networks, there is a clear separation between the generation of heating energy, its distribution and the transfer at the point of use. This conventional connection of the supply elements is not applicable when planning 5GDHC.

5GDHC are not only used for almost loss-free heat distribution but also as a heat source itself. These advantages of the network result from the low distribution temperatures of the heat transfer medium flowing through it. This leads to an interplay between the heat sources and the 5GDHC because the large-scale geothermal collector system does not have to cover the whole heat demand. The heat gains through the distribution pipes allows the other heat sources to be dimensioned smaller. The heat gains of the network itself are around $10-50 \%$ of the total required source heat demand. This leads to parallel planning of the heat sources together with the 5GDHC.

This connection between the heat sources (large-scale geothermal collector system, vertical ground heat exchanger field, air-cooled chiller plant, wastewater heat exchanger, etc.) and the distribution network currently represents the challenge in planning. Each heat source for itself can already be planned and dimensioned very well. Accordingly, in the planning procedure, the on-site available heat sources are first analyzed and selected. Then the 5GDHC can be planned and dimensioned according to the construction area. This process helps to assess whether an active or a passive network has to be realized. At this point, the heat gains of the network and the size of the heat sources can be estimated.

The (seasonal) shifting of heating and cooling energy between heat sources must be taken into account in the hydraulic planning of the overall system. Temporary heat surpluses from a wastewater heat exchanger, for example, can be stored in a large-scale geothermal collector system or a vertical ground heat exchanger field in order to provide them later for the $5 \mathrm{GDHC}$. To realize this shift, network sections need to operate autonomously without affecting the heat supply of the residential buildings.

Also, the heat extraction density is crucial when it comes to planning 5GDHC. It is important that the buildings are connected close to each other to get a high energy density within the network length. This leads to an economic use of the network. Otherwise, the earthwork per meter, the costs for the machinery and construction site equipment is mostly the same in less and very high dense areas. For economic reasons mostly only one heat source can be developed in less dense areas. Because of this there are no positive interactions between several heat sources within a 5GDHC. On the other hand, in some cases, the heat sources can be placed next to the settlement in rural areas which may lead to a passive network structure without the need for an energy center.

\subsection{Heat Gains from $5 G D H C$ Networks}

The planning of various implementation and research projects in Germany made apparent that the necessary source energy amount is also provided to a large extent by the 5GDHC itself. Because of non-insulated PE pipelines the 5GDHC functions like a horizontal geothermal collector that is extended in length. Heat gains are realized via the walls of the pipelines due to the temperature differences between the heat transfer medium and the surrounding soil.

The resulting heat gains of the network depend on the network temperature and the season. The higher the temperature difference and the longer the distribution pipes, the greater are the heat gains with the network. This can lead to area and cost savings of the large-scale geothermal collector system. However, the amount of the heat gains cannot be 
quantified in general terms. In addition, the temperature differences and pipe lengths, the surrounding soil conditions (soil type, moisture, thermal conductivity), climatic conditions (air temperature, solar irradiation, precipitation) and the main heat source of the network have a great impact. Currently, calculation tools are developed to improve the estimated heat gains and take those results into account when planning heat sources for 5GDHC [16].

In many projects in rural areas the energy demand density is rather low in contrast to cities, which leads to relatively long pipes. Two research projects "ErdEisII" (Grant N. 03ET1634A-E) and "KNW-Opt" (Grant N. 03EN3020A-F) as well as experiences from simulations showed that the distribution pipes can provide up to $50 \%$ of the annual source energy (see Table 2). Those 5GDHC networks are connected to a large-scale geothermal collector system. In denser residential structures heat gains through the grid can be about $20-40 \%$. The requirement is that the network temperatures are not permanently above the ground temperature, which is in most cases only possible with geothermal heat sources.

Table 2. Influence of the heat gains via the 5GDHC in combination with large-scale geothermal collector systems based on various implementation projects in Germany.

\begin{tabular}{cccc}
\hline & Number of Buildings & 5GDHC Pipe Length [m] & Heat Gains through 5GDHC [\%] \\
\hline 1 & 62 & 760 & $20 \%$ \\
2 & 159 & 3400 & $26 \%$ \\
3 & 256 & 5650 & $37 \%$ \\
4 & 180 & 6500 & $40 \%$ \\
5 & 61 & 1440 & $45 \%$ \\
\hline
\end{tabular}

The heat gains through the 5GDHC network in combination with large-scale geothermal collector systems can differ depending on the size of the collector system compared to the network length and heat distribution density. Network \#1 and \#5 from Table 2 have almost the same number of buildings connected to the 5GDHC network but different network length. Because of this, network \#5 doubles the network length compared to network \#1 which also doubles the heat gains through the network from 20 to $45 \%$. In this particular case, the large-scale geothermal collector system is dimensioned with equivalent specific heat extraction $\left(\mathrm{kWh} / \mathrm{m}^{2} \mathrm{y}\right)$ which leads to similar source and network temperatures. This is comparable because of similar climate conditions and heat conductivity of the locations soil.

The map displayed in Figure 8 shows that the soils heat conductivity for very shallow geothermal potential (vSGP) changes within Europe. Surrounding soil conditions with higher heat conductivity may lead to higher heat gains through the 5GDHC network. This map also shows that the identified dependence in Table 2 may work for countries with similar heat conductivity and climate condition as in Germany. Nevertheless, the most important factor is the relation of the large-scale geothermal collector system compared to the 5GDHC network length when it comes to the influence of the heat gains from the network itself. In general, lower network temperatures compared to the surrounding soil temperature lead to heat gains with non-insulated PE pipes.

Currently, there is a discussion in Germany about designing 5GDHC with double walls to ensure that the heat transfer medium does not escape the distribution pipes. Compared to the results shown in Table 2, this discussion is seen as very critical. This would lead to the fact that there are no more or significant fewer heat gains via the distribution network. This would mean that the source heat systems would have to be significantly larger in size, which would result in more space requirements and higher investment costs. 


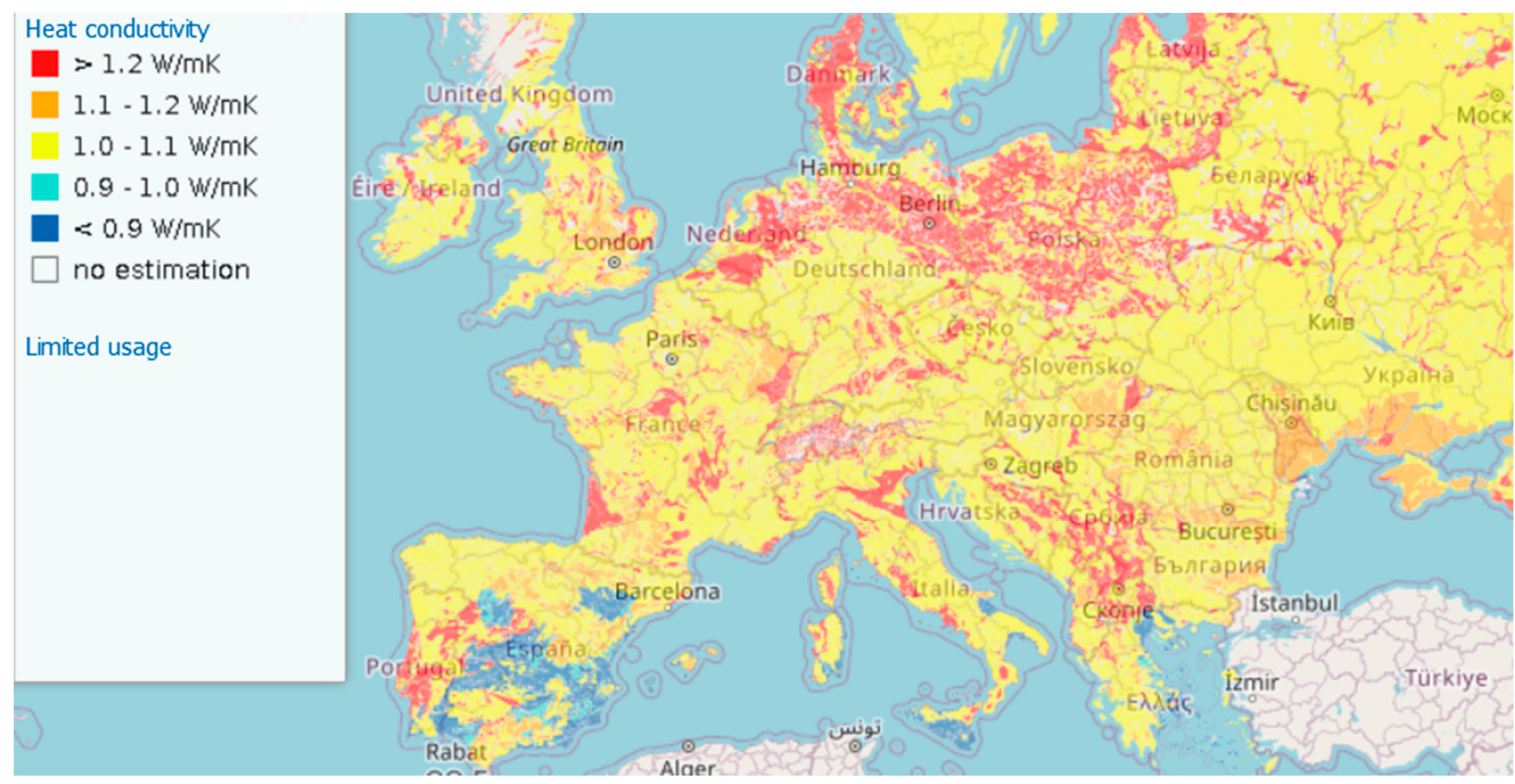

Figure 8. Heat conductivity map for different countries around Europe from vSGP (Source ThermoMap: https: / /www. thermomap.eu/, accessed on 20 May 2021).

\section{Conclusions}

In this paper large-scale-geothermal collector systems as a heat source for 5GDHC networks are defined and described. These collector systems use the very shallow geothermal potential in the first $10 \mathrm{~m}$ depth. In this depth, the regeneration energy for the collector system is mostly driven by the sun in the summer months rather than the terrestrial heat flow from inner depth.

As shown in this paper large-scale geothermal collector systems can be a very important energy source for 5GDHC networks. Some of the first projects in Germany are described to show that this technology is already used on a large-scale and is working properly for 5GDHC networks. In these projects, heating and cooling energy is used within the buildings through decentral heat pumps and floor heating systems. These networks are either constructed active or passive, which means the need for central pumps. This is depending on the network size, caused of the distance from the energy source to the settlement, the heat density as well as the number of connected buildings. In most cases settlements with more than 100 buildings are in the need of an active 5GDHC network, which means that there is an energy center with centralized network pumps.

Large-scale geothermal collector systems can also be built as multilayer collectors. In the lower collector layer, there is potential for seasonal heating and cooling energy shift. Because of the regeneration potential through solar irradiation there is also a new classification of the geothermal systems needed. There is already the classification of very shallow geothermal potential vSGP, which is accepted in this paper for these systems.

When it comes to 5GDHC the network itself can lead to significant heat gains caused by temperature levels around soil temperature. In combination with large-scale geothermal collector systems the heat gains from the network itself reach up to $50 \%$ of the heat demand, depending on network size and fluid temperature.

At the moment, most of these systems are working in central Europe with temperate climatic conditions. There is a clear difference between heating and cooling seasons, so the energy shift can be done. Future investigations are needed to transform this technology into warmer and cooler regions around the world. Indeed, 5GDHC networks are necessary for decarbonization of the heating and cooling sector. 
Author Contributions: Conceptualization, R.Z. B.O. and V.S.; investigation, R.Z. and B.O.; data curation, R.Z.; writing—original draft preparation, R.Z., B.O., D.P., T.K. and N.J.; writing-review and editing, R.Z., B.O. D.B. and V.S.; visualization, R.Z. and B.O.; supervision, V.S.; project administration, R.Z. All authors have read and agreed to the published version of the manuscript.

Funding: This research received no external funding.

Conflicts of Interest: The authors declare no conflict of interest.

\section{References}

1. Wang, Q.; Lin, J.; Zhou, K.; Fan, J.; Kwan, M.-P. Does urbanization lead to less residential energy consumption? A comparative study of 136 countries. Energy 2020, 202, 117765. [CrossRef]

2. United Nations. The Sustainable Development Goals Report 2020; United Nations Publications: New York, NY, USA, 2020.

3. Connolly, D.; Lund, H.; Mathiesen, B.V.; Werner, S.; Möller, B.; Persson, U.; Boermans, T.; Trier, D.; Østergaard, P.; Nielsen, S. Heat Roadmap Europe: Combining district heating with heat savings to decarbonise the EU energy system. Energy Policy 2014, 65, 475-489. [CrossRef]

4. European Council. European Council Meeting (10 and 11 December 2020)_Conclusions; EUCO 22/20; European Council: Brussels, Belgium, 2020.

5. Rezaie, B.; Rosen, M.A. District heating and cooling: Review of technology and potential enhancements. Appl. Energy 2012, 93, 2-10. [CrossRef]

6. $\quad$ Lund, H.; Werner, S.; Wiltshire, R.; Svendsen, S.; Thorsen, J.E.; Hvelplund, F.; Mathiesen, B.V. 4th Generation District Heating (4GDH). Energy 2014, 68, 1-11. [CrossRef]

7. Buffa, S.; Cozzini, M.; D'Antoni, M.; Baratieri, M.; Fedrizzi, R. 5th generation district heating and cooling systems: A review of existing cases in Europe. Renew. Sustain. Energy Rev. 2019, 104, 504-522. [CrossRef]

8. Weidlich, I. Wärmenetze. In Erneuerbare Energien; J.B. Metzler: Stuttgart, Germany, 2020; pp. 1203-1226.

9. Stănişteanu, C. Smart Thermal Grids-A Review. Sci. Bull. Electr. Eng. Fac. 2017. [CrossRef]

10. Sulzer, M.; Werner, S.; Mennel, S.; Wetter, M. Vocabulary for the fourth generation of district heating and cooling. Smart Energy 2021, 1, 100003. [CrossRef]

11. Boesten, S.; Ivens, W.; Dekker, S.C.; Eijdems, H. 5th generation district heating and cooling systems as a solution for renewable urban thermal energy supply. Adv. Geosci. 2019, 49, 129-136. [CrossRef]

12. Zeh, R.; Stockinger, V. Kalte Nahwärme-Wärme- und Kälteversorgung der Zukunft für Quartiere; Bd. 1; Ingenieur Spiegel, Public Verlag: Bingen, Germany, 2018; pp. 24-25.

13. Bünning, F.; Wetter, M.; Fuchs, M.; Müller, D. Bidirectional low temperature district energy systems with agent-based control: Performance comparison and operation optimization. Appl. Energy 2018, 209, 502-515. [CrossRef]

14. Sulzer, M.; Hangartner, D. Grundlagen-/Thesen Kalte Fernwärme (Anerigenetze); Hochschule Luzern Technik \& Architektur: Horw, Switzerland, 2014; pp. 1-10. Available online: https://www.researchgate.net/publication/262418798_Grundlagen-Thesen_ Kalte_Fernwarme_Anergienetze (accessed on 30 March 2021).

15. Vivian, J.; Jobard, X.; Hassine, I.B.; Hurink, J.; Pietruschka, D. Smart Control of a District Heating Network with High Share of Low Temperature Waste Heat. In Proceedings of the 12th Conference on Sustainable Development of Energy, Water and Environmental Systems, SDEWES 2017, Dubrovnik, Croatia, 4-8 October 2017.

16. Zeh, R.; Ohlsen, B.; Stockinger, V. Kalte Nahwärmenetze und Oberflächennaheste Geothermie im Urbanen Raum. bbr Technik Geothermie, Nr. 9, 2019. Available online: https://www.researchgate.net/publication/336412782_Kalte_Nahwarme_und_ oberflachennaheste_Geothermie_im_urbanen_Raum (accessed on 20 May 2021).

17. Brennenstuhl, M.; Zeh, R.; Otto, R.; Pesch, R.; Stockinger, V.; Pietruschka, D. Report on a Plus-Energy District with LowTemperature DHC Network, Novel Agrothermal Heat Source, and Applied Demand Response. Appl. Sci. 2019, 9, 5059. [CrossRef]

18. Lund, H.; Østergaard, P.A.; Chang, M.; Werner, S.; Svendsen, S.; Sorknæs, P.; Thorsen, J.E.; Hvelplund, F.; Mortensen, B.O.G.; Mathiesen, B.V.; et al. The status of 4th generation district heating: Research and results. Energy 2018, 164, 147-159. [CrossRef]

19. Blázquez, C.S.; Martín, A.F.; Nieto, I.M.; González-Aguilera, D. Economic and Environmental Analysis of Different District Heating Systems Aided by Geothermal Energy. Energies 2018, 11, 1265. [CrossRef]

20. Hähnlein, S.; Bayer, P.; Ferguson, G.; Blum, P. Sustainability and policy for the thermal use of shallow geothermal energy. Energy Policy 2013, 59, 914-925. [CrossRef]

21. Bertermann, D.; Klug, H.; Morper-Busch, L.; Bialas, C. Modelling vSGPs (very shallow geothermal potentials) in selected CSAs (case study areas). Energy 2014, 71, 226-244. [CrossRef]

22. Jocić, N.; Müller, J.; Požar, T.; Bertermann, D. Renewable Energy Sources in a Post-Socialist Transitional Environment: The Influence of Social Geographic Factors on Potential Utilization of Very Shallow Geothermal Energy within Heating Systems in Small Serbian Town of Ub. Appl. Sci. 2020, 10, 2739. [CrossRef]

23. Di Sipio, E.; Bertermann, D. Thermal properties variations in unconsolidated material for very shallow geothermal application (ITER project). Int. Agrophysics 2018, 32, 149-164. [CrossRef] 
24. Bertermann, D.; Schwarz, H. Laboratory device to analyse the impact of soil properties on electrical and thermal conductivity. Int. Agrophysics 2017, 31, 157-166. [CrossRef]

25. Schwarz, H.; Bertermann, D. Mediate relation between electrical and thermal conductivity of soil. Géoméch. Geophys. Geo-Energy Geo-Resources 2020, 6, 1-16. [CrossRef]

26. Bertermann, D.; Klug, H.; Morper-Busch, L. A pan-European planning basis for estimating the very shallow geothermal energy potentials. Renew. Energy 2015, 75, 335-347. [CrossRef]

27. Martinopoulos, G.; Papakostas, K.; Papadopoulos, A.M. A comparative review of heating systems in EU countries, based on efficiency and fuel cost. Renew. Sustain. Energy Rev. 2018, 90, 687-699. [CrossRef]

28. Pu, L.; Xu, L.; Qi, D.; Li, Y. Structure optimization for horizontal ground heat exchanger. Appl. Therm. Eng. 2018, 136, 131-140. [CrossRef]

29. Boban, L.; Miše, D.; Herceg, S.; Soldo, V. Application and Design Aspects of Ground Heat Exchangers. Energies 2021, 14, 2134. [CrossRef]

30. Agora, E. Die Energiewende im Corona-Jahr: Stand der Dinge 2020. In Agora Energiewende, 200/01-A-2021/DE, Berlin, 2021. Available online: https:/ / static.agora-energiewende.de/fileadmin/Projekte/2021/2020_01_Jahresauswertung_2020/200_AEW_Jahresauswertung_2020_WEB.pdf (accessed on 5 May 2021).

31. Bundesministerium für Wirtschaft und Energie. Entwicklung der Erneuerbaren ENergien in Deutschland im Jahr 2020. Available online: https://www.erneuerbare-energien.de/EE/Redaktion/DE/Downloads/entwicklung-der-erneuerbaren-energienin-deutschland-2020.pdf;jsessionid=ECD6A93191F2BB2E928CC694BCE1FEC5?_blob=publicationFile\&v=33 (accessed on 5 May 2021).

32. Bundesverband Wärmepumpe. Absatzzahlen für Warmwasserwärmepumpen in Deutschland 2020. Available online: https://www.waermepumpe.de/fileadmin/user_upload/Mediengalerie/Pressebilder/Absatzzahlen_Marktanteile/647_ Tabelle_AbsatzzahlenWP_2020.png (accessed on 5 May 2021).

33. S. B. STWB, 7,65 Millionen Euro vom Bund für Energieeffiziente Wärme im Bamberger Konversionsquartier Lagarde, Presseinformation: Stadtwerke Bamberg GmbH, 2020. Available online: https:/ /www.wiesentbote.de/2020/12/13/765-millionen-eurovom-bund-fuer-energieeffiziente-waerme-im-bamberger-konversionsquartier-lagarde/ (accessed on 20 May 2021).

34. Hahn, J.; Lauterbach, S.; Jensch, W. Netzdienliche Quartiere-Von der Konzeption bis zum Betrieb. In INUAS Konferenz Urbane Transformationen; HM Hochschule München: München, Germany, 2021; pp. 50-53.

35. Stäudinger, V.; Jensch, W.; Stockinger, V. ErdEis-Erdeisspeicher und Oberflächennahe Geothermie. Hochschule München, 2019. Available online: https:/ / www.researchgate.net/publication/334988393 (accessed on 5 May 2021).

36. Hirsch, H.; Petzold, H.; Grunewald, J. Efficiency and area demand of multi-layer ground heat exchanger using phase change of water. MATEC Web Conf. 2019, 282, 02027. [CrossRef]

37. Hirsch, H.; Hüsing, F.; Rockendorf, G. Modellierung oberflächennaher Erdwärmeübertrager für Systemsimulationen in TRNSYS. Dresden: BauSIM 2016. 2019. Available online: https://www.researchgate.net/publication/332655558_MODELLIERUNG_ OBERFLACHENNAHER_ERDWARMEUBERTRAGER_FUR_SYSTEMSIMULATIONEN_IN_TRNSYS (accessed on 5 May 2021).

38. Büchele, R.; Kranzl, L.; Hummel, M. What is the impact of the policy framework on the future of district heating in Eastern European countries? The case of Brasov. Energy Strat. Rev. 2018, 19, 72-75. [CrossRef]

39. Wirtz, M.; Neumaier, L.; Remmen, P.; Müller, D. Temperature control in 5th generation district heating and cooling networks: An MILP-based operation optimization. Appl. Energy 2021, 288, 116608. [CrossRef]

40. LaDR, L.B.-B. Neue Trinkwasserverordnung 2018. LaDR informiert, Nr. 257, 01/2018. Available online: https://www. safetyxperts.de/gesundheitsschutz/hygiene/gebaeudereinigung/trinkwasserverordnung/ (accessed on 20 April 2021).

41. John, G.; Hauke, H.; Hans, P. Implementation of a method for converting soil properties into building physical material properties. E3S Web Conf. 2020, 172, 14001. [CrossRef]

42. Blacha, T.; Mans, M.; Remmen, P.; Müller, D. Dynamic Simulation of Bidirectional Low-Temperature Networks-A Case Study to Facilitate the Integration of Renewable Energies. In Proceedings of the Building Simulation 2019: 16th Conference of IBPSA, Rome, Italy, 2-4 September 2019. 